\title{
Age-Related Surface Oxidases Shed into Body Fluids as Targets to Prevent Skin Aging and Reduce Cardiovascular Risk
}

\author{
D. James Morré ${ }^{1}$, Dale Kern², Christiaan Meadows', Helen Knaggs², Dorothy M. Morré1 \\ ${ }^{1}$ MorNuCo, Inc., Purdue Research Park, West Lafayette, USA \\ ${ }^{2}$ NuSkin International, Provo, USA \\ Email: dj_morre@yahoo.com
}

Received 28 January 2014; revised 3 March 2014; accepted 12 March 2014

Copyright (C) 2014 by authors and Scientific Research Publishing Inc.

This work is licensed under the Creative Commons Attribution International License (CC BY). http://creativecommons.org/licenses/by/4.0/

\section{Open Access}

\section{Abstract}

Age-related Ecto-Nicotinamide Adenine Dinucleotide Oxidase Disulfide Thiol Exchangers 3 (ENOX3) or age-related NADH oxidases (arNOX) are expressed at the cell surface as five members of the TM-9 superfamily, initially membrane anchored, all functionally similar, with the N-termini exposed at the cell's exterior. ECTO-NOXes are cell surface proteins with both time-keeping $\mathrm{CoQH}_{2}$ [NAD(P)H] oxidase and protein disulfide-thiol interchange activities. They are designated as ECTO-NOX proteins because of their localization on the outer surface of the plasma membrane and to distinguish them from the phox-NOXes of host defense. A ca. $30 \mathrm{kDa} \mathrm{N}$-terminal fragment is cleaved and accumulates in body fluids (serum, saliva, urine, perspiration). arNOXes appear around age 30 and increase steadily thereafter. Reduced quinones, i.e., reduced coenzyme $Q$, of the plasma membrane are natural substrates. NAD $(P) H$ is oxidized as an artificial substrate. In one phase of the arNOX cycle electrons are transferred to oxygen to generate superoxide. Substrates for the shed forms of arNOX appear to be proteins of body fluids. Circulating lipoproteins and skin matrix proteins emerge as potentially important health-related targets. Through oxidation of collagen, elastin and other proteins of the skin matrix, arNOXes are major contributors to skin aging through tyrosine and thiol oxidation and subsequent cross linking. The main destructive action of arNOX, however, may be to directly oxidize circulating lipoproteins. arNOX in the blood is structured as an integral component of the LDL particle through site-specific binding. As such, arNOXes are implicated as major risk factors for cardiovascular disease due to specific oxidation of LDLs. The superoxide produced and its conversion to hydrogen peroxide would be one part of the potentially destructive properties by contribution to lipid oxidation. Inhibition of arNOX proteins provides a rational basis for anti-aging interventions and their elimination as a major risk factor of atherogenesis.

\footnotetext{
*Corresponding author.
} 


\section{Keywords}

Atherosclerosis; Cardiovascular Risk; Age-Related NADH Oxidase (arNOX); TM9 Superfamily of Transmembrane Proteins; Serum and Body Fluids; Saliva; Skin Aging; Low Density Lipoproteins

\section{Introduction}

A growing number of pharmaceutical companies worldwide are engaged in programs to identify genes associated with the aging process as targets for anti-aging interventions (either to modulate gene expression at the level of messenger RNA or to modulate the protein products of the genes). The group of proteins designated as arNOX or age-related NADH oxidases, represent one such example as a family of aging genes amenable to such modulation (Figure 1). Age-related nicotinamide adenine dinucleotide oxidase (arNOX) proteins are one of several species of ECTO-NOX (external NADH oxidases) or ENOX proteins that have been postulated to link the accumulation of lesions in mitochondrial DNA to the cell surface accumulation of reactive oxygen species (ROS) [1] [2] and, as proteins shed into body fluids, to oxidize molecular targets at a distance from their tissues of origin [2].

The ENOX proteins are cell-surface located, terminal oxidases involved in the plasma membrane oxido-reductase (PMOR) system. Aging leads to the accumulation of mitochondrial DNA lesions and a shift towards energy production via glycolysis, resulting in a hyperactive-PMOR system. Generated superoxide can then form $\mathrm{H}_{2} \mathrm{O}_{2}$ and other ROS capable of damaging adjacent cells, circulating lipoproteins and the collagen and elastin components of the skin's extracellular matrix. The arNOX proteins are low or absent from individuals aged 20 to $40 \mathrm{y}$ or younger [3]. The activity appears at about age 30, reaches a peak between the ages of 55 to $65 \mathrm{y}$ in women and the ages of 65 to $75 \mathrm{y}$ in men [3] (Figure 2). In completed studies, high serum or salivary arNOX levels in subjects within these age ranges correlated with atherogenic risk and older-appearing skin [4] [5].

Age and oxidative stress are major risk factors for heart disease [6]. A large body of evidence supports the notion that reactive oxygen species provide a causal link in the appearance of circulating oxidized lipoproteins (i.e., oxidized low density lipoproteins) and their subsequent clearance by macrophages and delivery to the arterial wall (Figure 3). A major role of arNOX proteins in this process is now indicated [5].

arNOX proteins not only generate superoxide by transfer of single electrons to molecular oxygen but oxidize proteins as well [7]. arNOX-catalyzed oxidation and cross-linking of protein-bound tyrosines and measurements of Advanced Glycation Endproducts correlate with age and arNOX activity amenable to ablation by topical arNOX inhibitors, for example, to reduce skin aging. Inhibition of arNOX also provides a rational basis for the use of dietary or oral interventions to retard formation of aging-related arterial lesions through a reduction or prevention of LDL oxidation. Recognition of at least 5 isoforms of arNOX, their genetic cloning and the production of arNOX-specific polyclonal and monoclonal antibodies now leads us to look forward to interventions based on controlling gene expression and possibly mimicking gene expression profiles of younger skin and heart healthy

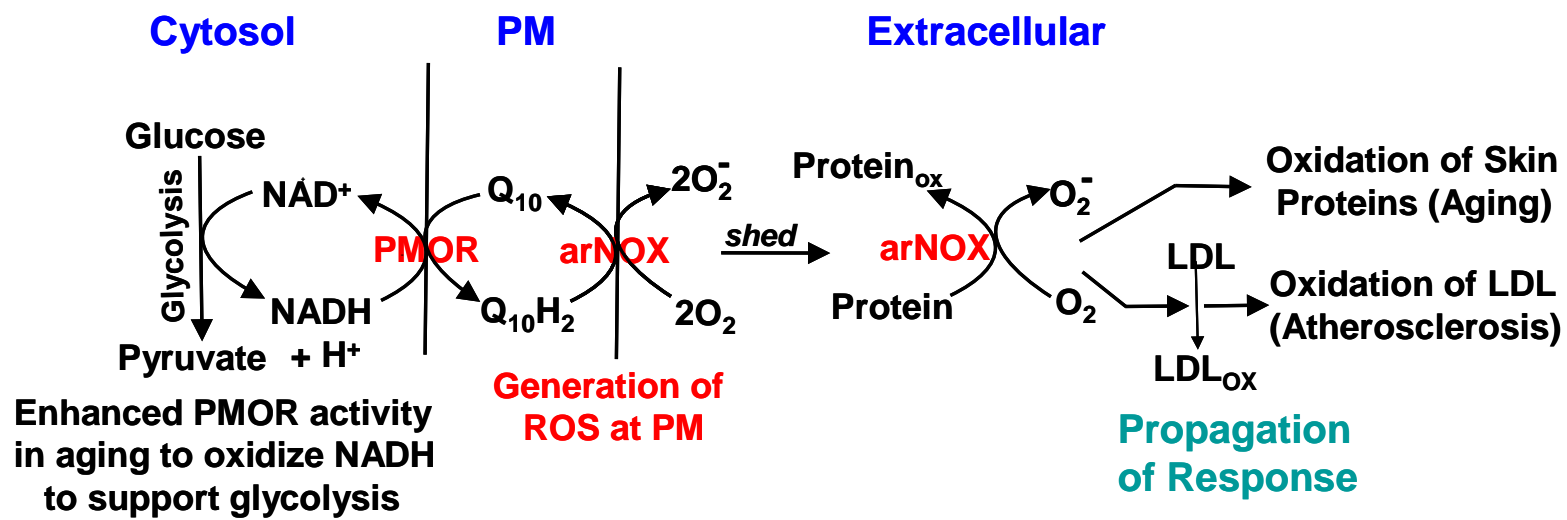

Figure 1. Generation of superoxide at the cell surface from the action of plasma membrane-situated arNOX activity (Modified from Morré et al. [2]). 


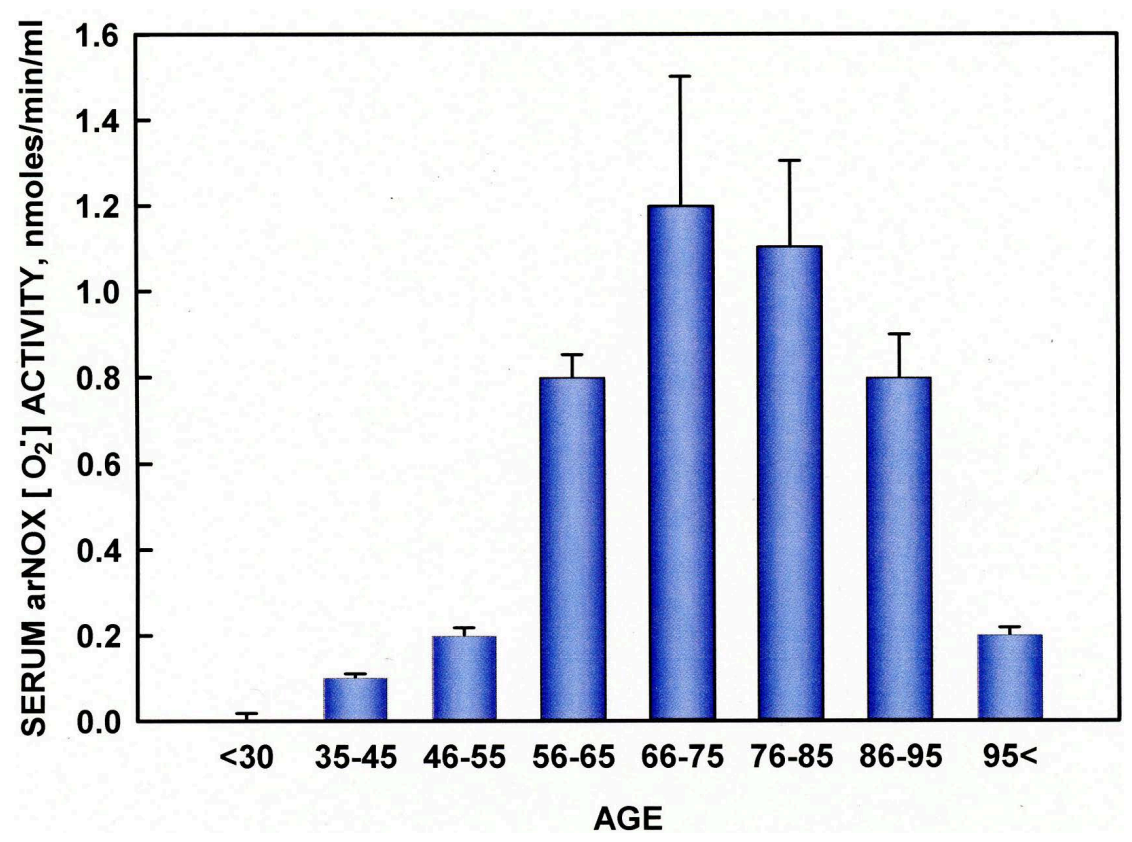

Figure 2. Serum arNOX correlates with age to a maximum between 66 and 75 years. Individuals reaching age 85 and beyond have reduced levels of serum arNOX.

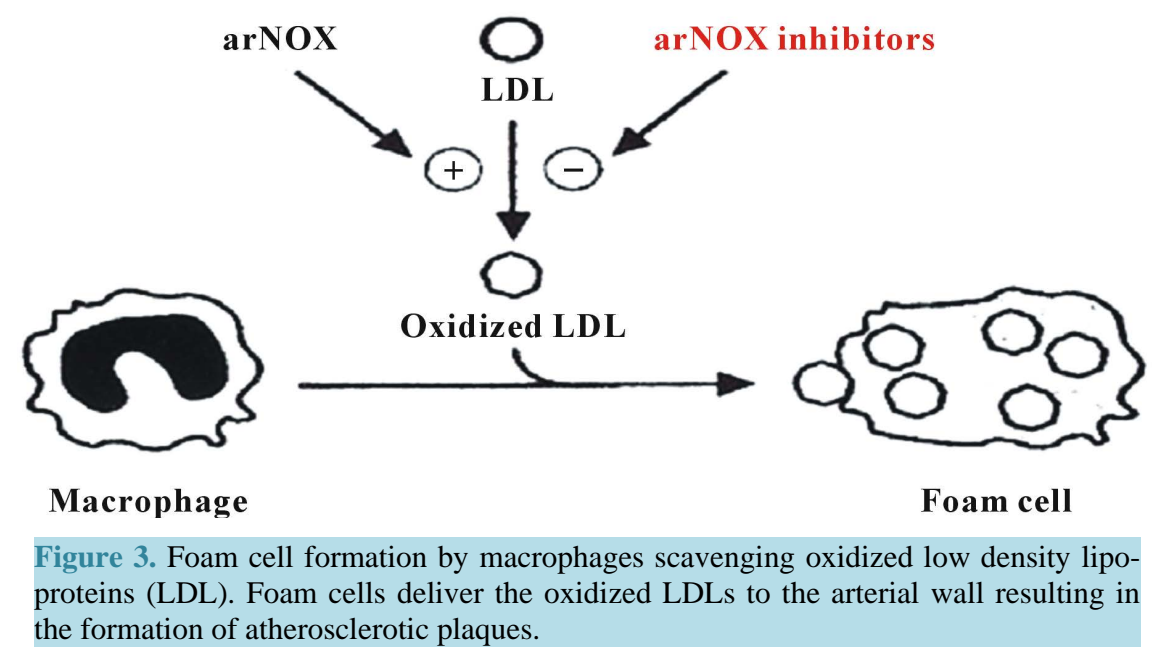

individuals. In this report, a potential new source of intrinsic ageing, the arNOX proteins, is described and data showing a correlation between elevated arNOX proteins and an aged appearance plus an increased cardiovascular risk are presented.

\section{Methods}

In aged volunteers, arNOX activity was found in sera, saliva, lymphocytes (buffy coats) and epidermis [8]. ArNOX activities from all sources correlated with age [9]. arNOX activity based on superoxide catalyzed reduction of ferricytochrome c was determined spectrophotometrically from absorbance at 550 nm with reference at $540 \mathrm{~nm}$ and inhibited by superoxide dismutase (SOD) [10]. Not only was arNOX activity observed in serum and saliva but in perspiration as well along with extracellular supporting matrices important to skin health. As with serum and saliva, arNOX activity of perspiration and skin increased with age. In addition to sera and perspiration, human saliva contains arNOX activity. Saliva offers an opportunity to readily monitor arNOX in patients and volunteers and to monitor responses to supplements. 
As a result of proteolytic cleavage, ca. $30 \mathrm{kDa}$ arNOX fragments are shed and enter the blood and other body fluids or are internalized into endosomes. The soluble fragments generate superoxide as estimated from the superoxide inhibited reduction of ferricytochrome c, a standard measure of superoxide production.

Levels of oxidized LDL in serum were measured by using a malondialdehyde protocol modified from Smith et al. [11]. Malondialdehyde equivalents were calculated for 1,1,3,3-tetramethoxypropane (Aldrich) standards.

Lipoproteins were isolated by flotation ultracentrifugation. Sera, saliva and perspiration of healthy volunteers were collected using Institutional Review Board (IRB)-approved protocols. Informed consent was used.

Unless stated otherwise, subjects were Caucasian, ages 25 to 98, enrolled from the greater Lafayette, IN area and both males and females in nearly equal numbers. Subjects for skin assessments were Caucasian females recruited in the Palo Alto, CA area.

Correlations used linear regression $(\mathrm{p}<0.001)$. Statistical comparisons of means with standard deviations used a two-tailed t-test (InStat). Values with non-overlapping standard deviations were highly significant ( $<<$ $0.001)$.

\section{Cloning}

At least three members of this family have been described so far: (1) the constitutive NADH oxidase (ENOX1 or CNOX), expressed in normal cells and located on chromosome 13q14.11 [8], (2) the tumour-associated NADH oxidase (also known as ENOX2 or tNOX), present on the surface of invasive cancer cells and located on chromosome Xq25-q26.2 [12], and (3) the age-related NADH oxidase (also named arNOX or Ecto-NOX3), consisting of 5 isoforms each located on a separate chromosome [12]. The first two family members were cloned in the last decade (GenBank Accession No. EF432052 and AF207881, for Ecto-NOX1 and Ecto-NOX2, respectively). The identity of arNOX or ENOX3 was determined only recently (GenBank Accession No. BK 008759) as members of the TM-9 family of ca $72 \mathrm{kDa}$ transmembrane proteins with transmembrane helices (Figure 4). Five isoforms are known so far based on sequences. arNOX is synthesized as a membrane anchored protein with its catalytic N-terminus directed toward the cell's exterior. Ca $30 \mathrm{kDa} N$-termini are then shed and circulate. Each of the shed isoforms has a unique peptide sequence. However, all of the shed forms have similar functional motifs characteristic of ENOX proteins. They are resistant to protease digestion (proteinase $\mathrm{K}$ ) and heat $\left(70^{\circ} \mathrm{C}-80^{\circ} \mathrm{C}\right)$ as istypical of the ENOX proteins. Moreover, they all catalyze oscillation patterns of redox activities which impart a time-keeping function, arNOX proteins are a novel discovery made more important by the paucity of biomarkers which serve as aging-related indicators of cardiovascular oxidative damage amenable to the- rapeutic intervention. As a potentially important parameter of antioxidant defenses and oxidative stress, measurements of arNOX may be used to determine whether an intervention achieves its intended biochemical or

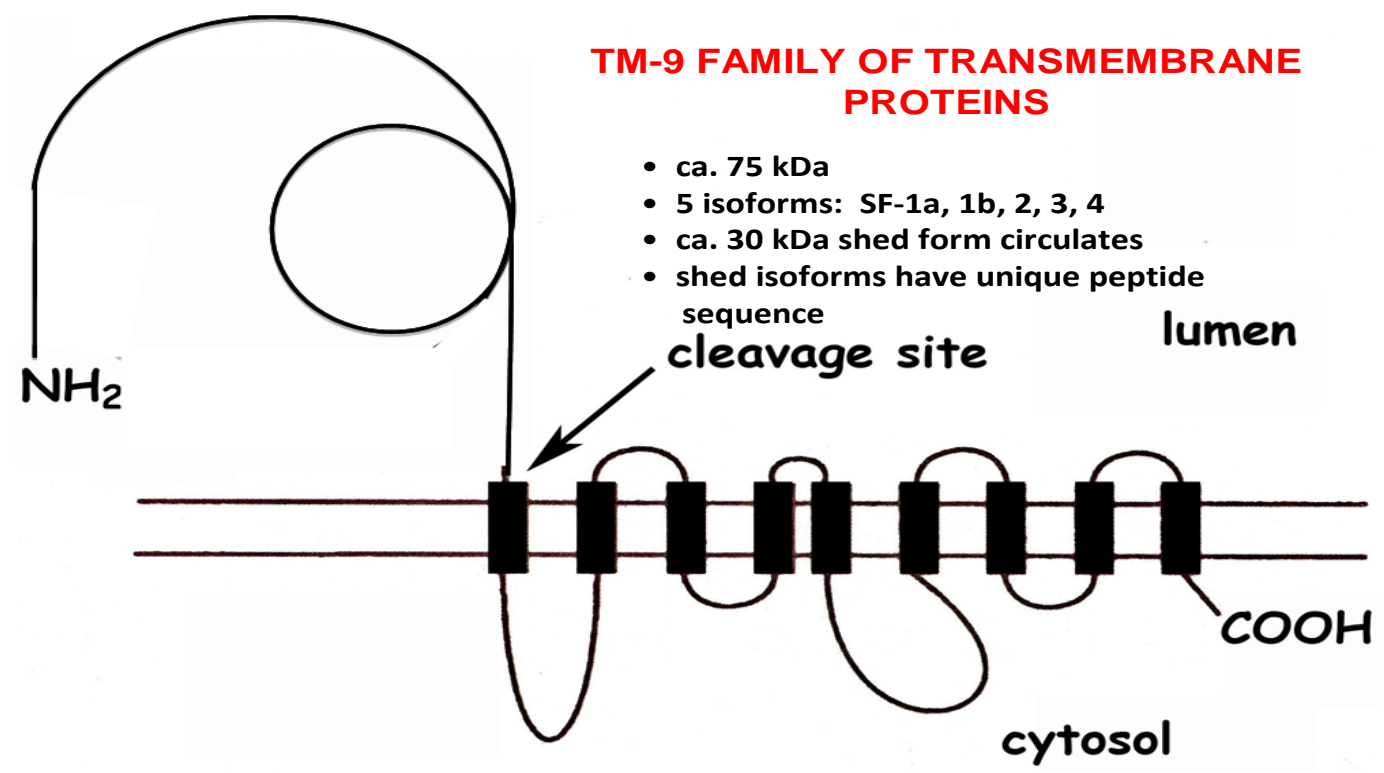

Figure 4. arNOX proteins are members of the TM9 family of transmembrane proteins. 
physiological endpoint or whether the enrolled subjects in a clinical trial present with oxidative stress at the beginning of the trial. Thus, a reliable biomarker correlated with aging such as arNOX has the potential to give guidance to the design and outcome measures of clinical trials with age-related disorders. Moreover, research exploring agents capable of inhibiting arNOX has been greatly facilitated by the availability of recombinant arNOX proteins. Specific nutritional supplements to prevent or slow aging are expected to represent a major advance in human nutrition and nutritional supplements. Identification of the arNOX gene and its gene products, for example, has allowed strategies to seek drugs, botanicals and natural non-botanical substances that slow or block both aging and atherogenic processes.

\section{Results}

\section{1. arNOX and Skin Health}

arNOX (ENOX3) activity of skin increases with age beginning at age 30 as determined for both dermis and epidermis (Figure 5). The arNOX generates superoxide and reactive oxygen at the cell surface, significantly increasing the ratio of production of reactive oxygen species (ROS) vs. antioxidant defense. This increase greatly accelerates the age-related changes due to lipid and/or protein oxidation. Hence, agents that reduce this activity are anticipated to have value for anti-aging intervention, since arNOX emerges as a compelling molecular target to explain how coenzyme $\mathrm{Q}_{10}$ and other anti-aging substances offer protection to maintain skin vitality [8].

The arNOX proteins, being very stable to heat, proteolysis and chemical degradation,are released into the outer layers of the skin, for example, where it oxidizes skin proteins such as collagen and elastin by converting thiols to disulfides and by converting tyrosines to tyrosyl radicals. The latter then react to cross-link proteins through dityrosyl linkages as a major factor in altering skin texture and appearance, in wrinkle formation and other degenerative conditions related to skin aging [13]. arNOX is found in both the epidermis and dermis at both sun-exposed and non-sun exposed sites [14].

Evidence to link arNOX activity levels to oxidative changes during aging includes correlation with Advanced Glycation Endproduct (AGE) readings estimated using a Dianoptic (San Diego, CA) fluorescence AGE reader [15] [16] (Figure 6). Oxidation end products (fluorescent adducts of oxidized lipids and proteins) normally accumulate with aging. A light source excites fluorescent moieties in the tissue which then emit light of a different

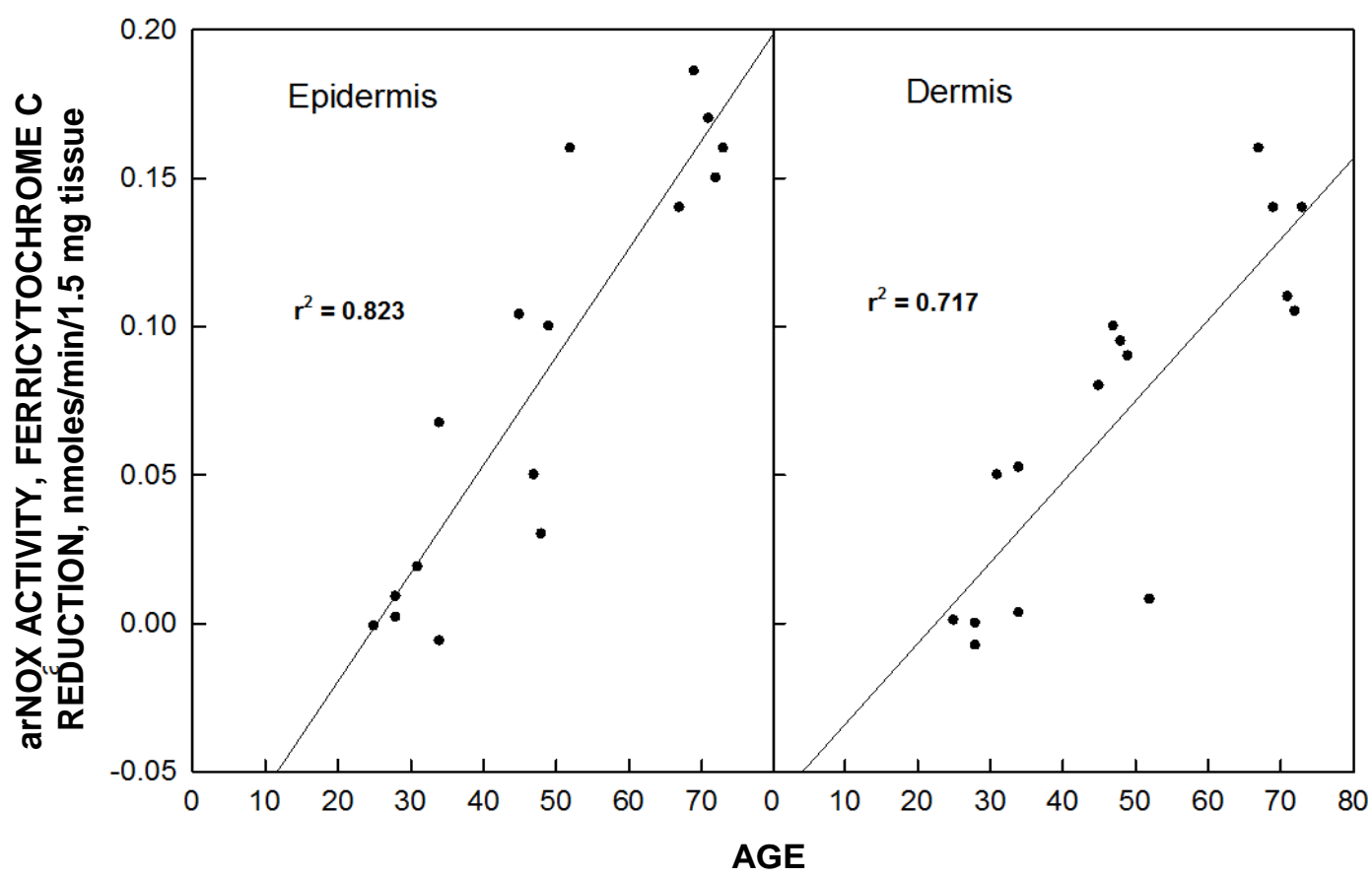

Figure 5. arNOX activity of epidermal and dermal explants of skin increase with age beginning about age 30 . The subjects were females. Values of activities susceptible to inhibition by superoxide dismutase did not become measurable until after age 30 . 


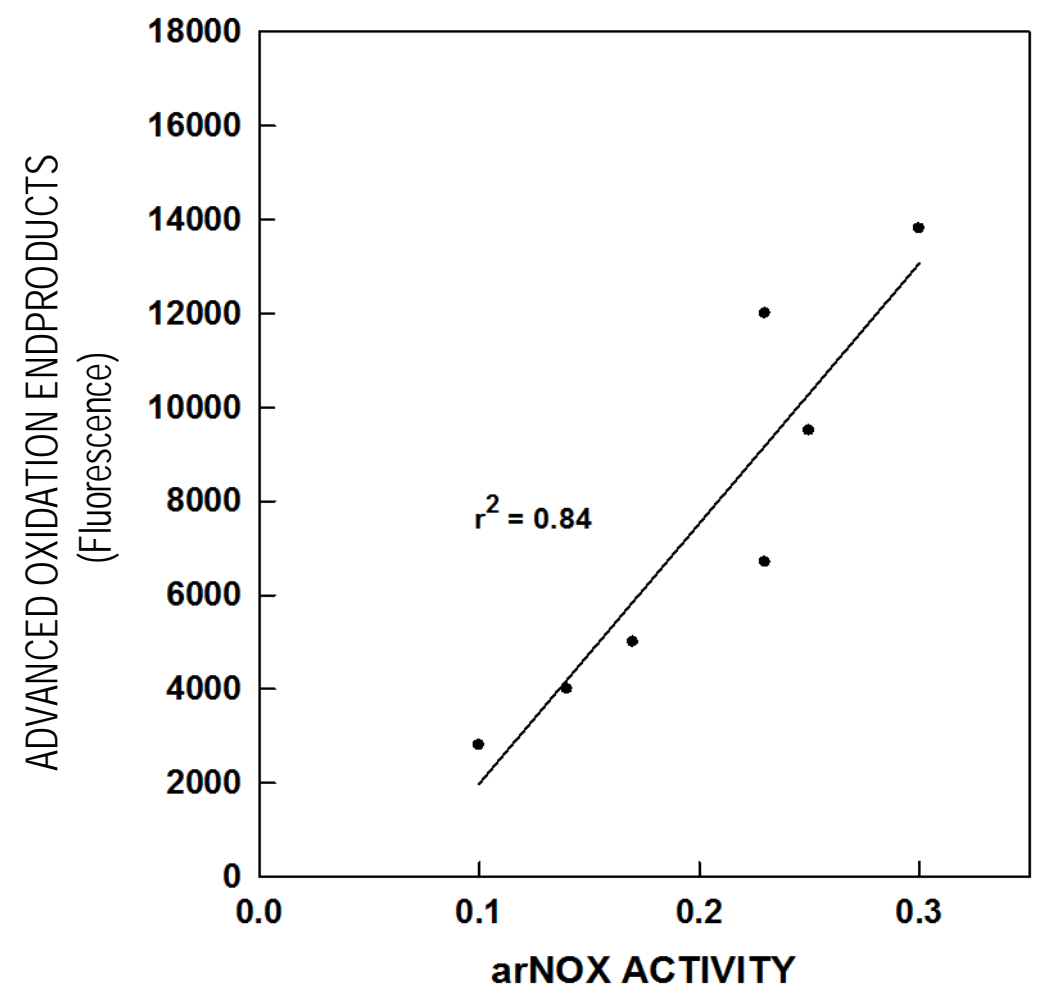

Figure 6. Advanced glycation oxidation endproducts rise as arNOX activity of sera increase with increasing age.

wavelength. In the wavelength band used, the major contribution to fluorescence came from fluorescent AGE linked to proteins, mostly to collagen.

To correlate mean error in estimating age with arNOX, studies were conducted with female subjects. Independent graders reviewed photographs of close-ups of subject's faces taken at a baseline visit and estimated each subject's age. The graders estimated age and scored skin according to overall skin health, fine wrinkling, deep wrinkling, skin color, skin laxity, pore size and evenness. Estimates of age were averaged and compared to the subject's actual age. Age differences and other skin assessment scores were compared to arNOX levels determined from serum, saliva and sweat collections (Figure 7). Subjects with high arNOX activity had skin characteristics that made them appear on average $7 \mathrm{y}$ older than their chronological age whereas subjects with low arNOX activity at the same age had on average 7 y younger-appearing skin than their actual age. arNOX activity in skin cells that increased with age was shown as well for primary keratinocytes and fibroblasts from human donors [17].

Thus, the hypothesis under investigation is that arNOX proteins are a major cause of oxidative protein damage in the outer layers of the skin and that arNOX inhibitors would be of cutaneous value in persons between ages of 45 and 65. The findings suggest that arNOX oxidizes skin proteins, collagen and elastin, directly as a source of electrons to generate superoxide. Tyrosines are especially susceptible to oxidation by arNOX and when oxidized to tyrosyl radicals, the tyrosyl radicals form cross links in the protein. Since the arNOX is shed, it is able to migrate into the outer layers of the epidermal epithelium to carry out extracellular protein oxidation. Since arNOX appears to be overexpressed with increasing age, these potentially destructive molecules will persist even in the face of genetic changes affecting protein renewal and their inhibition presents potentially safe and effective anti-aging strategies whereby skin ageing is controlled directly at its source.

\section{2. arNOX and Coronary Artery Disease}

Age and oxidative stress are major risks for heart disease [6]. The causal link is the generation in the circulation of oxidized low density lipoproteins (LDLs) and their subsequent clearance by macrophages and delivery to the arterial wall [18]. The process of internalizing the oxidized particles transforms the macrophages into foam cells. 


\section{7 years younger $/ 7$ years older}

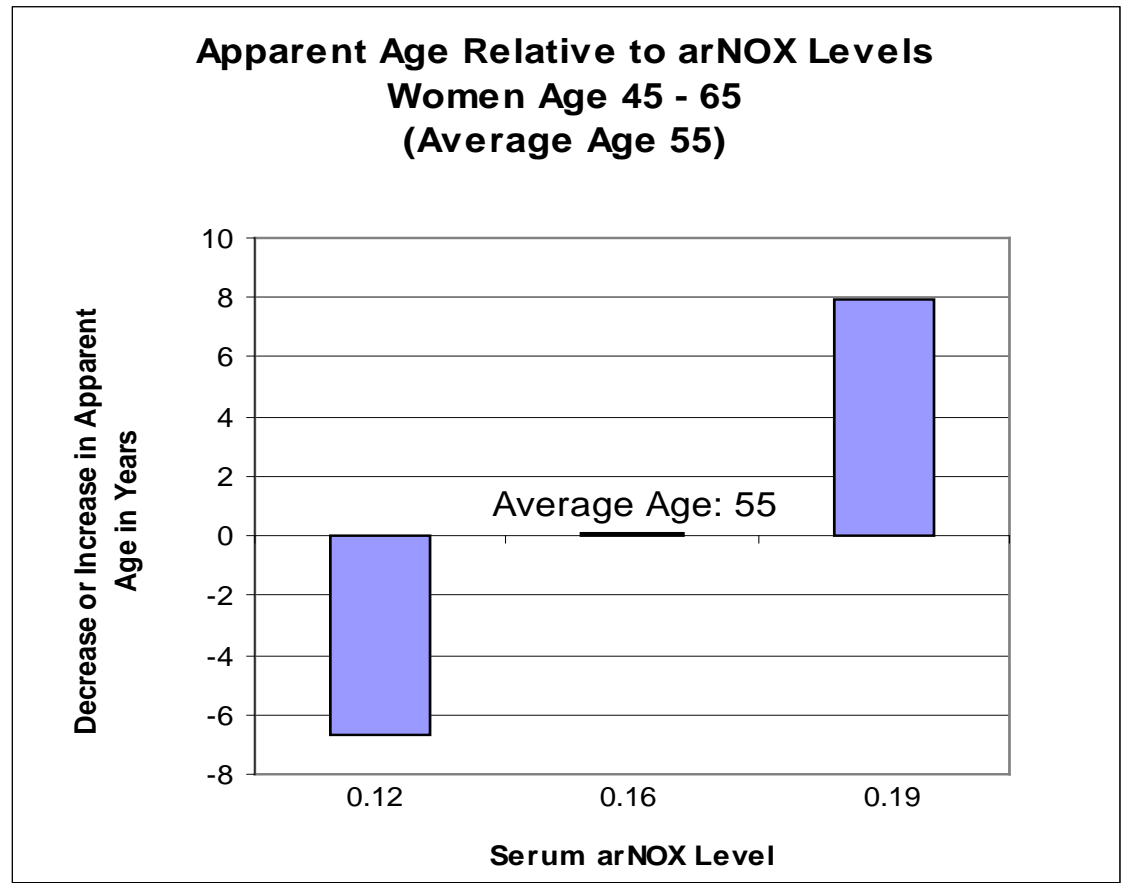

Figure 7. Serum arNOX activity is correlated with mean error in estimating age. Sera were collected from 25 female subjects and compared to ages estimated from photographs taken at the same time. From Rehmus et al. [13].

If oxidation of lipoprotein particles was prevented or significantly reduced by oral inhibitors of arNOX, the lipoprotein particles would not be internalized to create foam cells and deposits beneath the arterial intimae would be greatly reduced as a result.

However, until now there has not been a clear cause as the basis for LDL oxidation in the blood. Levels of most antioxidants including $\alpha$-tocopherol, $\beta$-carotene and ascorbate decline with age in the elderly but there is no apparent correlation between ingestion of these common antioxidants and amelioration of the aging process or decreased mortality [19]. The implication is that the oxidative damage leading to aging and increased atherogenic risk is the result of a much more specific causation. A correlation with levels of arNOX activity may explain why LDL oxidation increases in the elderly and is greater in some individuals than in others. arNOX proteins appear after age 30 and increase to a maximum at about age 55 to 65 in women and age 65 to 75 in men in direct correlation to atherogenic risk. Of those who die of a heart attack, $85 \%$ are age 65 or older [20]. Women surviving beyond age 65 usually have diminished arNOX levels compared to men and a lower risk of coronary artery disease compared to men [21] further suggesting some causal relationship between ar NOX levels and atherogenic risk.

A number of observations point to arNOX as a primary generator of reactive oxygen species (ROS) in the body, especially with regard to oxidation of circulating lipoprotein particles. arNOX proteins actually bind to LDLs and utilize thiol groups as the source of electrons transferred to oxygen to form superoxide or to oxygen to form water. Not only does arNOX activity result in oxidation of the lipid core with formation of malondialdehyde-like adducts but the LDL coat proteins are oxidized as well in supplying electrons to the oxidase [22].

arNOX in the blood appears to be structured as an integral component of the LDL particle in that, after overnight flotation centrifugation, $30 \%-40 \%$ of the arNOX is associated with the lipoprotein particles. The LDLassociated arNOX floats up through saline or distilled water and cannot be washed off. The TM94 arNOX family member that binds LDL has a 27 amino acids sequence with $40 \%$ similarly to the LDL receptor binding surface (Figure 8). Not only does arNOX of sera target the apoB of LDL particles as an electron source for superoxide formation, the arNOX emerges as being complexed with its apoB target. Thus, much of the oxidative damage is through direct oxidation of protein thiols and tyrosines. 


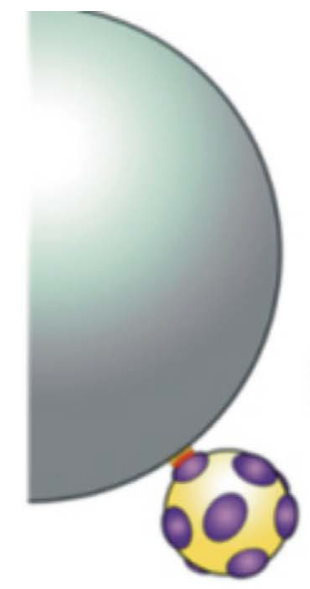

(a)

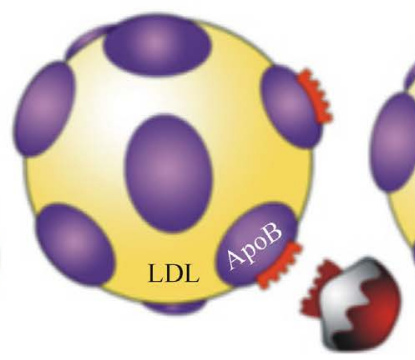

(b)

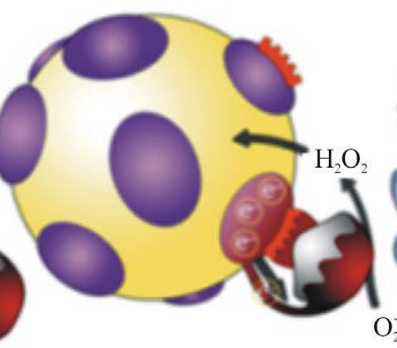

(c)

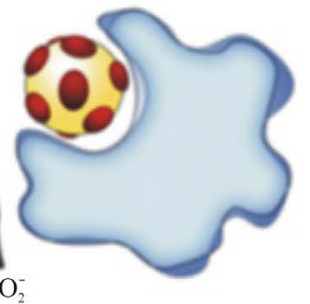

(d)

Figure 8. Cartoon illustrating the role of arNOX in lipoprotein oxidation. a) LDL particles bind to LDL receptors on the cell surface to initiate lipid delivery to peripheral cells. b) arNOX attaches to ApoB receptor by a portion of their sequence similar to that of the cell surface LDL receptor in a) c) The arNOX attaches to the ApoB, withdrawing electrons to generate superoxide $\left(\mathrm{O}_{2}^{-}\right)$. The superoxide is then converted to lipid oxidizing $\mathrm{H}_{2} \mathrm{O}_{2}$ by superoxide dismutase. d) Oxidized LDL particles are recognized by macrophages and internalized to form foam cells leading to atherosclerosis.

The pathway of the role for arNOX in apoB oxidation and subsequent pathology requires formation of lysine adducts [12] with malondialdehyde derived from ROS-catalyzed lipid oxidation as an obligatory step [23]. Formation of malondialdehyde-like products in human serum lipoproteins correlated previously with arNOX levels in a cell free co-incubation system [24]. ROS generation from superoxide would ensure superoxide dismutase catalyzed dismutation of superoxide to form $\mathrm{H}_{2} \mathrm{O}_{2}$.

Mitochondria appear not to be a major source of cellular superoxide anion or hydrogen peroxide. Uninhibited respiring mitochondria produce very little of either [25]-[27]. The actual amount of $\mathrm{H}_{2} \mathrm{O}_{2}$ produced by mitochondria appears to be in the order of $0.1 \mathrm{nmoles}$ formed $/ \mathrm{min} / \mathrm{mg}$ mitochondrial protein. In contrast, in the elderly, the bulk of the superoxide anion and $\mathrm{H}_{2} \mathrm{O}_{2}$ appears to be produced by the plasma membrane or exterior to the cells themselves. At peak production which occurs on average at about age 65, approximately 0.06 nmoles/ min superoxide is produced $/ 10^{7}$ cells (human buffy coat or epidermal epithelia) [13]. The value in sera is approximately $0.3 \mathrm{nmoles} / \mathrm{ml} / \mathrm{min}$ which results in several millimoles of superoxide being produced on a daily basis in the proximity of circulating lipoproteins just from the circulating form.

\section{Discussion}

Structure-activity analysis and related arNOX blocking molecules have been used to identify arNOX substrate blocking molecules appropriate to anti-aging interventions. Some identified supplement candidates are efficiently absorbed and extremely effective at dilutions corresponding to $<100 \mathrm{ng} / \mathrm{ml}$ or approximately $0.1 \mathrm{mg} / \mathrm{kg}$ body weight. Included are gallic acid, salicin, tyrosol, and coenzyme $\mathrm{Q}_{10}$ (Table 1 ).

The basic premise is that the arNOX protein provides a molecular target to explain how coenzyme $\mathrm{Q}_{10}$ and other anti-aging substances could offer protection to maintain skin vitality and possibly ablate aging-related cardiovascular changes. arNOX is inhibited by coenzyme $\mathrm{Q}_{10}$, a substance long implicated as having anti-aging properties but for which there was no clear biochemical rationale to completely explain its effects (Figure 9). Relative arNOX activities of sera correlate with those of saliva making salivary arNOX an attractive indicator of the efficacy of arNOX inhibitors in clinical trials.

A second platform for a dietary intervention strategy directed toward reducing aging-related cardiovascular risk is based on the inhibition of arNOX by certain culinary seasonings often referred to as "Herbs de Provence," all of which are ingredients used extensively in the French kitchen [28]. A possible explanation for the French Paradox is provided by these observations where the French diet or lifestyle leads to reduced atherogenic risk despite a cholesterol-rich diet high in cheese and butter. Previous studies attributed the reduction in risk to con- 
Table 1. Specific inhibitors of arNOX activity.

\begin{tabular}{ccc}
\hline EC $_{80}$ & TM9SF2 & TM9SF4 \\
\hline arNOX Block $^{\mathrm{a}}$ & $1: 30$ & $1: 20$ \\
CoQ $_{10}$ & $30 \mathrm{nM}$ & $50 \mathrm{nM}$ \\
Tyrosol & $3 \mu \mathrm{M}$ & $1 \mu$ \\
Gallic Acid & $2 \mu \mathrm{M}$ & $2 \mu \mathrm{M}$ \\
\hline
\end{tabular}

${ }^{\mathrm{a}} 60 \mu \mathrm{L}$ of an aqueous mixture of $4 \mathrm{mg} / \mathrm{mL}$ Schizandra chinensis extract, 9\% schizandrins (Draco, San Jose CA), plus $1 \mathrm{mg} / \mathrm{mL}$ salicin (Sigma, St. Louis, MO), and $20 \mu \mathrm{L}$ of IBR Dormin (Israeli Biotechnology Research, Ramat-Gan, Israel) added to $2.5 \mu \mathrm{L}$ of assay volume.

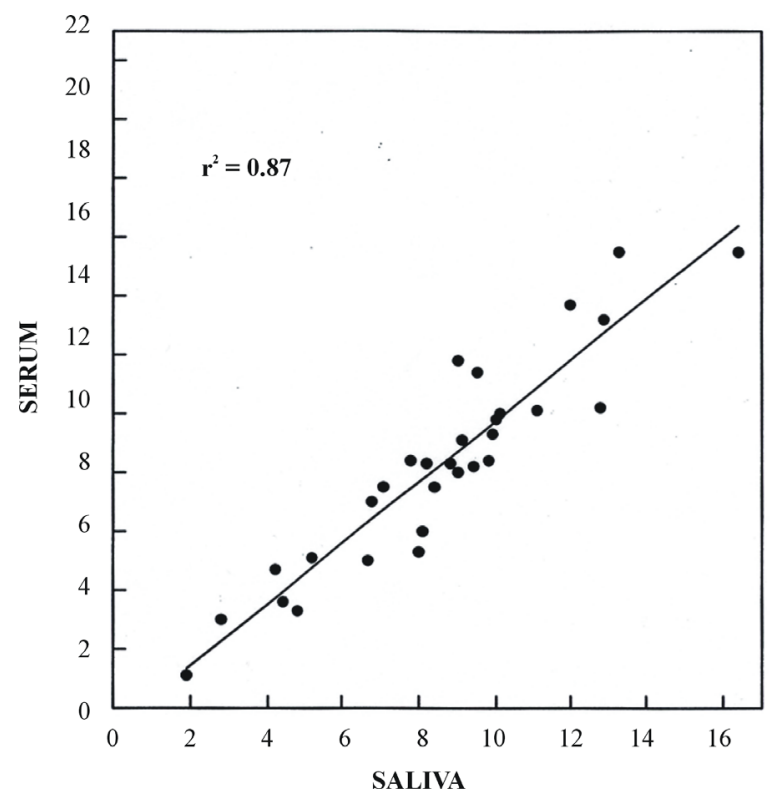

Figure 9. arNOX activities of sera and saliva correlate.

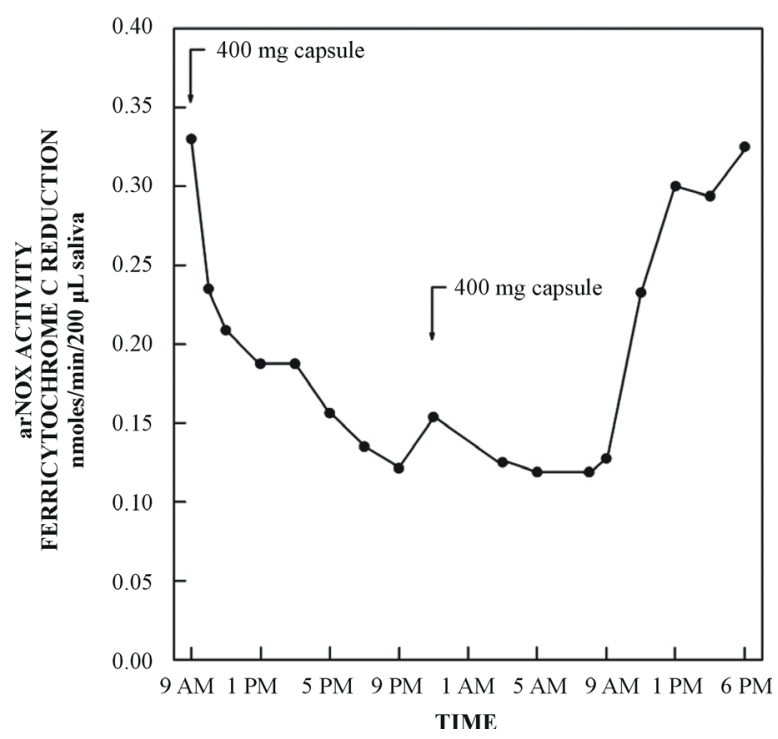

Figure 10. Inhibition of serum arNOX by finely ground savory supplied as a sustained release formulation. 
sumption of red wine as a natural source of the polyphenol resveratrol [29]. However, the herbs which are staples of the French diet offer a more compelling explanation as resveratrol is only very poorly absorbed into the blood stream in man [30] [31].

Inhibitions by herbal infusionsat a final concentration of $7.5 \mu \mathrm{g} / \mathrm{mL}$ in the assay varied from $50 \%$ to $90 \%$ for savory, estragon (tarragon), basil, majoram, rosemary and sage along with a corresponding inhibition of arNOX catalyzed lipid oxidation. Savory and estragon (tarragon) were effective at concentrations as low as $75 \mathrm{ng} / \mathrm{mL}$ in the assay. Also effective were gallic acid at a final concentration of $2 \mu \mathrm{M}(340 \mathrm{ng} / \mathrm{mL})$ and tyrosol at 1 to $3 \mu \mathrm{M}$ (138 to $414 \mathrm{ng} / \mathrm{mL}$ ).

By formulating the herbal preparations as sustained-release preparations, $24 \mathrm{~h}$ of protection were attained with just two 400-mg capsules/day (one in the morning and one before bedtime) (Figure 10). It is this aspect that makes possible a therapeutic utility of the technology to reduce aging-related arterial damage from oxidized circulating lipoproteins in individuals as they age beyond 30 years. Ablation of reactive oxygen species important to skin ageing has been achieved by topical arNOX inhibitors. Recognition of a least 5 isoforms of arNOX, their genetic cloning and the production of arNOX-specific polyclonal and monoclonal antibodies now leads us to look forward to intervention based on controlling gene expression and possibly mimicking gene expression profiles of younger skin.

\section{References}

[1] Morré, D.J. and Morré, D.M. (2003) Cell Surface NADH Oxidases (ECTO-NOX proteins) with Roles in Cancer, Cellular Time-Keeping, Growth, Aging and Neurodegenerative Disease. Free Radical Research, 37, 795-808. http://dx.doi.org/10.1080/1071576031000083107

[2] Morré, D.M., Lenaz, G. and Morré, D.J. (2000) Surface Oxidize and Oxidative Stress Propagation in Aging. The Journal of Experimental Biology, 203, 1513-1521.

[3] Morré, D.J. and Morré, D.M. (2008) arNOX Activity of Saliva as a Non-Invasive Measure of Coenzyme $\mathrm{Q}_{10}$ Response in Human Trials. BioFactors, 32, 231-235. http://dx.doi.org/10.1002/biof.5520320127

[4] Morré, D.M, Meadows, C., Hostetler, B., Weston, N., Kern, D., Draelos, Z. and Morré, D. J. (2009) Age-Related ENOX Protein (arNOX) Activity Correlated with Oxidative Skin Damage in the Elderly. BioFactors, 34, 237-244. http://dx.doi.org/10.1002/biof.5520340308

[5] Morré, D.M., Meadows, C. and Morré, D.J. (2010) arNOX: Generator of Reactive Oxygen Species in the Skin and Sera of Aging Individuals Subject to External Modulation. Rejuvenation Research, 13, 162-164. http://dx.doi.org/10.1089/rej.2009.0919

[6] Schmuck, A., Fuller, C. J., Devaraj, S. and Jialal, I. (1995) Effect of Aging on Susceptibility of Low-Density Lipoproteins to Oxidation. Clinical Chemistry, 41, 1628-1632.

[7] Morré, D.J. (2004) Quinone Oxidoreductases of the Plasma Membrane. Methods in Enzymology, 378A, 179-199. http://dx.doi.org/10.1016/S0076-6879(04)78015-5

[8] Morré, D.J. and Morré, D.M. (2013) ECTO-NOX Proteins. Springer, New York.

[9] Morré, D.J. and Morré, D.M. (2006) Aging-Related Cell Surface ECTO-NOX Protein, arNOX, a Preventive Target to Reduce Atherogenic Risk in the Elderly. Rejuvenation Research, 9, 231-236. http://dx.doi.org/10.1089/rej.2006.9.231

[10] Butler, J., Koppeol, W.H. and Margoliash, E. (1982) Kinetics and Mechanism of the Reduction of Ferricytochrome c by the Superoxide Anion. Journal of Biological Chemistry, 257, 10747-10750.

[11] Smith, J.B., Ingerman, C.M. and Silver, M.J. (1976) Malondialdehyde Formation as an Indicator of Prostaglandin Production by Human Platelets. Journal of Laboratory and Clinical Medicine, 88, 167-172.

[12] Tang, X., Parisi, D., Spicer, B., Morré, D.M. and Morré, D.J.(2013) Molecular Cloning and Characterization of Human Age-Related NADH Oxidase (arNOX) Proteins as Member of the TM-9 Superfamily of Transmembrane Proteins. Adcances in Biological Chemistry, 3, 187-197. http://dx.doi.org/10.4236/abc.2013.32024

[13] Kern, D.G., Draelos, Z.D., Meadows, C., Morré, D.J. and Morré, D.M. (2010) Controlling Reactive Oxygen Species in Skin at Their Source to Reduce Skin Aging. Rejuvenation Research, 13, 165-167. http://dx.doi.org/10.1089/rej.2009.0914

[14] Rehmus, W.E., Kern, D., Janjua, R., Morré, D.M., Morré, D.J. and Knaggs, H. (2008) Appearance of Skin Ageing in Healthy Women. Correlation with arNOX Levels: A Potential New Mechanism in Ageing? Clinical Dermatology, Retinoids: Other Treatments, 24, 52-56.

[15] Reznick, A.Z. and Packer, L. (1994) Oxidative Damage to Proteins: Spectrophotometric Method for Carbonyl Assay. Methods in Enzymology, 233, 357-363. http://dx.doi.org/10.1016/S0076-6879(94)33041-7 
[16] Terada, T., Takada, K., Yamanishi, H. and Ashida, Y. (2007) Inhibitory Effects of Coenzyme Q 10 on Skin Aging. Abstracts. 5th Conference of the International Coenzyme $Q_{10}$ Association, Kobe, 156.

[17] Knaggs, H. (2009) The arNOX Enzyme: Implications for Intrinsic Aging. Cosmetics and Toiletries, 124, 48-52.

[18] Holvoet, P. (1999) Endothelial Dysfunction, Oxidation of Low-Density Lipo-Protein, and Cardiovascular Disease. Therapeutic Apheresis and Dialysis, 3, 287-293. http://dx.doi.org/10.1046/j.1526-0968.1999.00169.x

[19] Bjelakovic, G., Nikolova, D., Gluud, L.L., Simonetti, R.G. and Gluud, C. (2007) Mortality in Randomized Trials of Antioxidant Supplements for Primary and Secondary Prevention: Systematic Review and Meta-Analysis. JAMA, 297, 842-857. http://dx.doi.org/10.1001/jama.297.8.842

[20] American Heart Association Statisitcal Update (2008) Heart Disease and Stroke Statistics-2008. Circulation, 117, e25e146.

[21] Kannel, W.B. and Lavine, B.S. (2003) Coronary Heart Disease Risk in People 65 Years of Age and Older. Progress in Cardiovascular Nursing, 18, 135-140. http://dx.doi.org/10.1111/j.0889-7204.2003.01947.x

[22] Ferguson, E., Singh, R.J., Hagg, N. and Kalyanaraman, B. (1997) The mechanism of Apolipoprotein B-100 Thiol Depletion during Oxidative Modification of Low-Density Lipoprotein. Archives of Biochemistry and Biophysics, 341, 287-294. http://dx.doi.org/10.1006/abbi.1997.9975

[23] Gillotte, K.L., Hörkkö, S. Witztum, J.L. and Steinberg, D. (2001) Oxidized Phospholipids, Linked to Apolipoprotein B of Oxidized LDL, Are Ligands for Macrophage Scavenger Receptors. Journal of Lipid Research, 41, 824-833.

[24] Morré, D.M. and Morré, D.J. (2006) Coenzyme Q and Lipid Oxidation in Aging and Cardiovascular Disease. Absracts, 41st Annual South Eastern Regional Lipid Conference, Cashiers, 1-3 November 2006, 68.

[25] Nohl, H., Kozlov, V., Staniek, K. and Gille, L. (2001) The Multiple Functions of Coenzyme Q. Bioorganic Chemistry, 29, 1-13. http://dx.doi.org/10.1006/bioo.2000.1193

[26] Nohl, H., Gille, L. and Staniek, K. (2005) Intracellular Generation of Reactive Oxygen Species by Mitochondria. Biochemical Pharmacology, 69, 719-723. http://dx.doi.org/10.1016/j.bcp.2004.12.002

[27] St. Pierre, J., Buckingham, J., Roebuck, S.J. and Brand, M.D. (2002) Topology of Superoxide Production from Different Sites in the Mitochondrial Electron Transport chain. Journal of Biological Chemistry, 277, 44784-44790. http://dx.doi.org/10.1074/jbc.M207217200

[28] Morré, D.J., Morré, D.M. and Shelton, T.B. (2010) Aging-Related Nicotinamide Adenine Dinucleotide Oxidase Response to Dietary Supplementation: The French Paradox Revisited. Rejuvenation Research, 13, 159-161. http://dx.doi.org/10.1089/rej.2009.0918

[29] Teissedre, P.L. and Waterhouse, A.L. (2000) Inhibition of Oxidation of Human Low-Density Lipoproteins by Phenolic Substances in Different Essential Oil Varieties. Journal of Agricultural and Food Chemistry, 48, 3801-3805. http://dx.doi.org/10.1021/jf990921x

[30] Walle, T., Hsieh, F., DeLegge, M.H., Oatis, Jr., J.E. and Walle, U.K. (2004) High Absorption But Very Low Bioavailability of Oral Resveratrol in Humans. Drug Metabolism and Disposition, 32, 1377-1382. http://dx.doi.org/10.1124/dmd.104.000885

[31] Vitaglione, P., Sforza, S., Galaverna, G., Ghidini, C., Caporaso, N., Vescovi, P.P., Fogliano, V. and Marchelli, R. (2005) Bioavailability of Trans-Resveratrol from Red Wine in Humans. Molecular Nutrition \& Food Research, 49, 495-504. http://dx.doi.org/10.1002/mnfr.200500002

\section{Abbreviations}

AGE: Advanced glycation end product

$\mathrm{CoQH}_{2}$ : Reduced coenzyme Q (ubiquinol)

ENOX: ECTO-NOX

ENOX1 (CNOX): Constitutive cell surface NADH oxidase

ENOX2 (tNOX): Tumor-associated cell surface NADH oxidase

ENOX3: Age-related cell surface NADH oxidase

LDL: Low density lipoprotein

ROS: Reactive oxygen species

SF: Superfamily

SOD: Superoxide dismutase

TM: Transmembrane 